\title{
Reciprocal Meter
}

National Cancer Institute

\section{Source}

National Cancer Institute. Reciprocal Meter. NCI Thesaurus. Code C42573.

The SI unit of wave number, the spatial analogue of frequency; closely related to the concept of the wave vector. 